\title{
Greenhouse Gas Emission Reporting Mechanism for Hotel Industry: A Case of Sri Lanka
}

\author{
Lebunu Hewage Udara Willhelm Abeydeera ${ }^{1 *}$ and Gayani Karunasena ${ }^{2}$ \\ ${ }^{1}$ The Hong Kong Polytechnic University, Hong Kong \\ ${ }^{2}$ Deakin University, Australia
}

Submission: July 05, 2019; Published: July 25, 2019

*Corresponding author: Lebunu Hewage Udara Willhelm Abeydeera, PhD Student, The Hong Kong Polytechnic University, Hung Hom, Hong Kong

\begin{abstract}
Greenhouse Gas (GHG) Emissions have been recognized as one of the most significant factors that affect the global climate change. Many researches have indicated that tourism sector has a high impact to the global GHG emissions. Number of organizations have introduced GHG emission reporting mechanisms that can be adhered to report the emissions. Reporting the GHG emissions (or calculating the carbon footprint) is recognized as the primary step of the GHG emission mitigation process. However, these reporting mechanisms do not have industry specific guidelines which is identified as a major drawback. Purpose of this study is to establish a GHG emission reporting mechanism for hotel industry with specific emphasis to Sri Lanka. Based on the Case study approach a qualitative analysis has been carried out in five of the five-star hotels located in the commercial capital of Sri Lanka. The outline derived for the emission reporting mechanism is the key finding of this study which can be used to develop a GHG emission reporting guideline for hotel industry.
\end{abstract}

Keywords: Hotels; Sri Lanka; GHG Emission; Reporting; Carbon

\section{Introduction}

United Nations World Tourism Organization [UNWTO] [1] has reported that the international tourists have increased from 25 million to 1186 million during the period of 1950 and 2015. As a result, the economic impact of tourism industry has also increased remarking $9 \%$ of GDP of the world [1]. According to the statistics of UNWTO [2] Sri Lanka has recorded the highest number of tourist arrivals in 2015 and the numbers have increased from 0.6 million to 1.7 million during the 2010-2015 period. Sri Lankan Tourism Development Authority [SLTDA] [3] has exclaimed that tourism industry will account for $3.7 \%$ of the total Sri Lankan GDP in 2024. Apart from the economy, culture, human life and climate have been affected either positively or negatively by the tourism industry. UNWTO (2011) has addressed climate change as the largest challenge that will be faced by the humankind in the 21st century and hotel industry has been recognized as a key contributor to the GHG emissions. Deng [4] indicates that the predicted amount of carbon emissions due to energy use in the hotel industry is significant and Ricaurte [5] and Joseph et al. [6] has indicated that due to the unavailability of a proper method to determine the carbon emissions from hotels, the facilities managers and other professionals have been unable to identify their contribution to GHG emissions. Therefore, the emissions caused by the hotels have gone unnoticed in most of the circumstances. Ricaurte [5] has further indicated that GHG emissions reporting as the initiative of a sustainable approach.
Therefore, it is evident that the hotel industry is in need of a proper GHG emission reporting mechanism that can be used universally.

Many of the global accommodation providers have initiated the process of recording their carbon emissions in different formats and has no widely adopted method [5]. Dascalaki \& Balaras [7] further exclaims that the need for uniform carbon footprint calculation of a hotel is paramount, yet it is not the only sustainability performance metric. As per Scheur, Keoleian \& Reppe [8] Carbon footprint is also recognized as a required element for achieving sustainability. As a response to the requests made by the guests, stakeholders and investors many hotels have developed platforms to become sustainable [5].

In this context, it has become a necessity to provide a basis to implement specific guideline for hotel industry. Under these circumstances this research paper was focused on developing an outline to prepare a GHG emission reporting mechanism for hotel industry. Identification of globally recognized standards and practices used for GHG emission reporting, determining the awareness and current practices of GHG emission reporting in the Sri Lankan hotel sector and developing an outline for GHG emission reporting in Hotels were the three main objectives set to achieve the primary aim of this study. Initially, the paper discusses the current situation of GHG emissions and emission 
reporting in the global context. Then the paper focus on the methodology, findings and finally a discussion on findings is presented with the developed outline for reporting GHG emissions in the hotels. The study was limited to large scaled hotels in the commercial capital of Sri Lanka.

\section{Literature Findings}

A comprehensive literature survey was carried out in order to identify the existing practices of GHG emission reporting around the world. This review signifies the importance of having a proper GHG emission reporting method not only for the hotel industry but also for many other industries as well.

\section{Greenhouse gas emissions}

World Resources Institute [WRI] [9] has indicated China, United States, European Union, India, Russian Federation, Japan and Canada as the leading GHG emitters. Majority of these emissions were recorded from fossil fuel combustions, gas flaring and cement manufacturing. According to IPCC [10] tropical deforestations in Asia, Africa and South America have also contributed to the GHG emissions in a higher scale. In order to identify the impact of Greenhouse Gas emissions, it is essential to recognize and differentiate the greenhouse gases and their impacts. Furthermore, it is necessary to recognize the impact of tourism industry towards GHG emissions. This section aims to identify and discuss the above-mentioned aspects in detail.

\section{Greenhouse Gases And Global Warming Potential (GWP)}

Intergovernmental Panel on Climate Change [IPCC] [11] has listed down number of gases with a potential for global warming. It is further stated in IPCC [11] that these gases have accounted for nearly $77 \%$ of total global $\mathrm{CO}_{2}$ equivalent greenhouse gas (GHG) emissions. IPCC [11] has declared the GWP indicator which represents the GWPs of the major greenhouse gases. Table 1 indicates these dominant gases and their global warming potential in $\mathrm{CO}_{2}$ equivalent.

Table 1: Global warming potentials of different gases.

\begin{tabular}{|c|c|c|}
\hline Gas & Formula & Global Warming Potential \\
\hline Carbon dioxide & $\mathrm{CO}_{2}$ & 1 \\
\hline Methane & $\mathrm{CH}_{4}$ & 25 \\
\hline Nitrous oxide & $\mathrm{N}_{2} \mathrm{O}$ & 298 \\
\hline HFCs & - & $124-14800$ \\
\hline Sulphur hexafluoride & $\mathrm{SF} 6$ & 22800 \\
\hline PFCs & - & $7390-12200$ \\
\hline
\end{tabular}

\section{Source: IPCC [11].}

According to above Table 1 it is evident that several gases have a high potential of global warming. Therefore, these gases have been named as the greenhouse gases. Ramachandra, Aithal and Sreejith [12] has indicated that the concentration of GHG in the atmosphere has been continuously increasing due to the anthropogenic activities performed. Thus, has resulted in an increase of the global temperature which has been identified as the global warming issue by Ramachandra, Aithal and Sreejith [12].

\section{Greenhouse gas emissions by industry}

Indian Network for Climate Change Assessment [INCCA] (2010) [13] has classified power generation (energy), industrial and commercial activities, agricultural activities, activities related to land use and land changes and waste handling as the main sectors of GHG emission in the Indian context. US Greenhouse gas inventory of US Environmental Protection Agency [USEPA] (2015) has made a similar classification for GHG emission sectors. EEA (2014) has also classified the GHG emissions under the above categories and has added an additional category, solvent and other product use.

IPCC [10] has indicated following six categories as the key emission sources of greenhouse gases.

a) Agriculture, Forestry and Other Land Use (AFOLU)

b) Industry

c) Transport

d) Buildings

e) Energy

f) Waste

IPCC [10] has recognized energy as the leading GHG emitting sector while AFOLU has been reported as the second highest greenhouse gas emitting sector. Buildings and transport sectors have almost an identical level of GHG emissions. Comparison of the sectorial GHG emission levels is available in Figure 1.

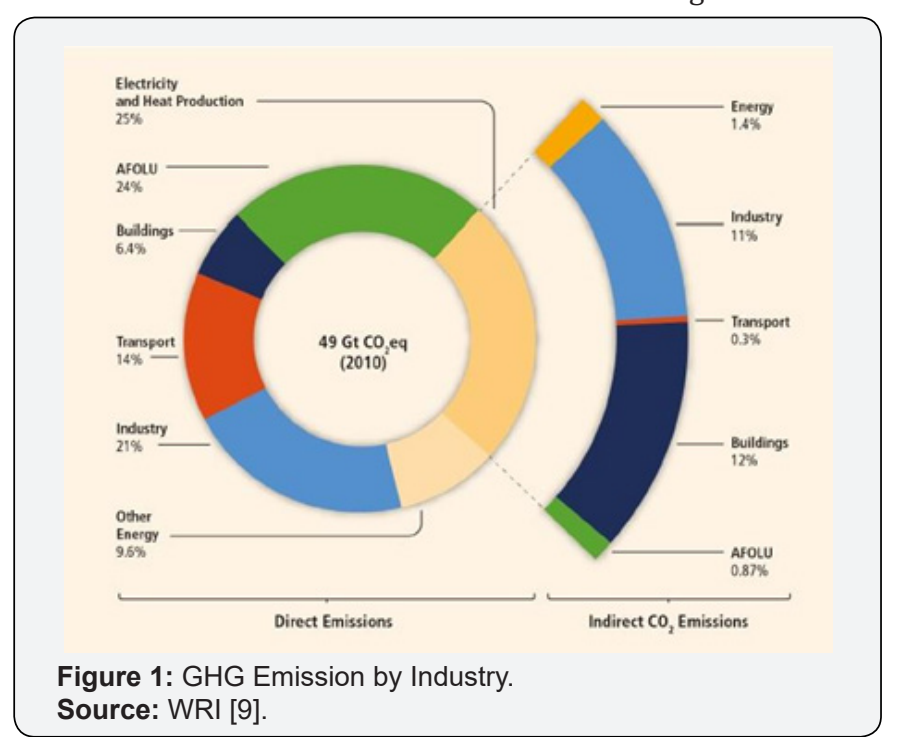

According to Figure 1 it is clear that electricity and heat production has the highest impact on the global GHG emission level. It is a combination of several elements such as energy, industry, transport, buildings and AFOLU. Further it is evident that the building sector accounts for the highest contribution in electricity and heat production related emissions. 


\section{Greenhouse gas emissions of the tourism industry}

Dubois \& Ceron [14] has stated that tourism accounts for 4-10\% of global GHG emissions annually. Above stats have been confirmed by UNWTO [15] and has further indicated that in 2005 tourism accounted for almost 5\% of the global GHG emissions. IPCC [10] has indicated that the contribution of tourism sector is rising continuously. Further it is stated in IPCC [10] that the impact of tourism industry has been in the range of $3.9 \%$ to $6 \%$ of the global emissions and has the potential to rise up to $130 \%$ within the next two decades.

Transportation accounts for the highest portion of GHG emissions in the tourism industry (UNWTO, 2014). It is further explained in UNWTO (2014) that transport accounts for $75 \%$ of the GHG emissions of the tourism sector in which $40 \%$ is from aviation, $32 \%$ from road transport and the $3 \%$ from the other forms of transportation. Furthermore UNWTO (2014) has stated that accommodation sector has a contribution of $21 \%$ for the tourism sector emissions.

When the accommodation sector is considered large hotels had a higher impact to the emissions than guest houses, selfcatering apartments or campgrounds. This is due to the extra facilities in the large hotels such as restaurants, spas and bars which consume more energy [16]. Impact of the other

Table 2: Global Standards used for GHG emission reporting.

\begin{tabular}{|c|c|}
\hline Standard & Content Summary \\
\hline Kyoto Protocol & $\begin{array}{l}\text { It was only after the Kyoto Protocol the world began to understand the importance of recording GHG emissions. } \\
\text { This protocol is included with three key mechanisms, emission trading, Clean Development Mechanism (CDM) and } \\
\text { Joint Implementation (JI) (UNFCCC, 2012). }\end{array}$ \\
\hline $\begin{array}{l}\text { Intergovernmental } \\
\text { Panel on Climate Change } \\
\text { Regulations }\end{array}$ & 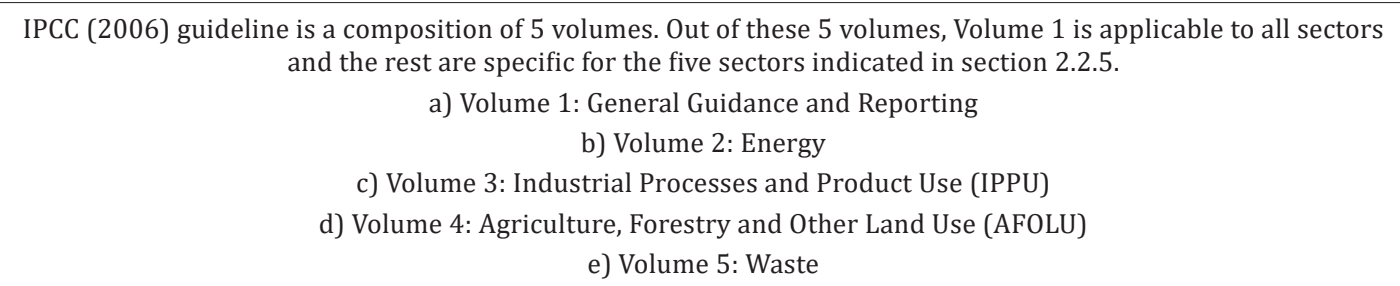 \\
\hline $\begin{array}{l}\text { International Organization } \\
\text { for Standardization (ISO) } \\
\qquad 14064\end{array}$ & $\begin{array}{l}\text { ISO } 14064 \text { is recognized as one of the most systemized approaches for reporting GHG emissions in organizational } \\
\text { contexts. Under the general title of Greenhouse gases ISO } 14064 \text { is included with three parts. } \\
\text { a) Part 1: Organization level guidance through specifications for quantification and reporting of greenhouse gas } \\
\text { emissions and removals. } \\
\text { b) Part 2: Project level guidance with specifications for quantification, monitoring and reporting of approaches } \\
\text { related to mitigation of greenhouse gas emissions } \\
\text { c) Part 3: Specifications required for validation and verification of greenhouse gas assertions }\end{array}$ \\
\hline $\begin{array}{l}\text { International Sustainability } \\
\text { and Carbon Certification } \\
\text { Guidelines }\end{array}$ & $\begin{array}{l}\text { In order to calculate and report GHG emissions of the supply chain, ISCC guidelines were introduced. Under this } \\
\text { guideline following areas of the supply chain can be evaluated for the emissions. } \\
\text { a) Biomass producers } \\
\begin{array}{r}\text { b) Conversion units (Conversion of solid biomass into liquid biomass or processing of liquid biomass) } \\
\text { c) Transport and distribution }\end{array} \\
\text { This guideline provides the basis for carrying out a systematic audit of GHG emissions in the supply chain. }\end{array}$ \\
\hline $\begin{array}{l}\text { Global Environmental } \\
\text { Facility Guidelines }\end{array}$ & $\begin{array}{l}\text { This manual addresses the aspects such as energy efficiency, renewable energy, and clean energy technology along } \\
\text { with their impact to the GHG emissions. GEF has developed he guideline with the support of IPCC (2006) guideline } \\
\text { and elements such as good practice and key categories have been widely addressed in the GEF guideline as well. }\end{array}$ \\
\hline
\end{tabular}

As mentioned above, Ricaurte [5] has emphasized the fact that there is no proper standard method for GHG emission reporting for the hotels. Accordingly, key elements required for GHG emission reporting were derived from the above indicated tourist activities depend on its relationship with the energy consumption. Wang \& Huang (2013) has indicated that energy consumption of hotels is different to other building categories and they further stated that the energy consumption of hotels differs based on the geographical location which can result in high GHG emissions. Taylor, Peacock, Banfill \& Shao (2010) have stated that the likeliness of hotel management to provide a high level of comfort to the guests have resulted in high emissions from the hotels. As a result, hotels have been recognized as a high emission source in the non-domestic building category (Taylor, Peacock, Banfill \& Shao, 2010).

\section{Greenhouse gas emissions reporting}

Kyoto Protocol addressed the requirement of having a proper GHG reporting mechanism due to the need of mitigating the hazard of increasing GHG emissions. Based on these circumstances number of institutes have put forward guidelines to be followed when reporting GHG emissions. These guidelines include number of different processes and functions which are required to be followed. Joshep, Yik \& Man [6] has exclaimed that there is no sufficient literature to analyze carbon emissions of individual buildings. However, there are emission reporting standards published by many organizations. Following standards are recognized as some of the key standards related to GHG emission reporting (Table 2). standards. IPCC volume 1, part 1 of ISO 14064 [17], ISCC guideline and the elements of GEF guideline were used to identify the key elements required for emission reporting process in hotels. 


\section{Key elements of greenhouse gas emission reporting in hotels}

When determining the operational aspects emission reporting shall be done under the following three categories.

Direct: The emissions recorded through direct operations of the hotel should be discussed under this section.

Energy Indirect: There are number of buildings associated with the operations of a hotel (eg: main building, restaurants etc.). Emissions from these buildings shall be recorded under this section.

Table 3: Sources of GHG emissions in Hotels.
Other Indirect: All the indirect sources of emissions which are not categorized under the above two scopes shall be included under this category. E.g.: business travels of hotel employees, employee commuting etc.

It is essential to follow up a sequential process when carrying out the GHG emission reporting. If not key elements will be missed in the data collection and evaluation process. Thus, will result an outcome that has considerable variations from the actual results. Key focus sectors of GHG emission reporting in the hotels are presented in Table 3.

\begin{tabular}{|c|c|c|c|}
\hline \multirow{4}{*}{ Energy } & Source & Classification & Description \\
\cline { 2 - 4 } & Electricity use & $\begin{array}{c}\text { Energy } \\
\text { Indirect }\end{array}$ & $\begin{array}{c}\text { The use of electricity in the hotel premises for all the purposes shall be } \\
\text { recorded. }\end{array}$ \\
\hline \multirow{4}{*}{ Transportation } & Vehicle Fleet & $\begin{array}{c}\text { Direct/ Other } \\
\text { Indirect }\end{array}$ & $\begin{array}{c}\text { If the appliance causing the emissions are operated by the hotel it will be } \\
\text { classified under direct, else it will be classified under other indirect scope }\end{array}$ \\
\cline { 2 - 4 } & $\begin{array}{c}\text { Employee Commuting (Single } \\
\text { Occupancy Vehicle) }\end{array}$ & Other Indirect & The vehicles used for commuting the employees of the hotel to their \\
\cline { 2 - 4 } & Business Related Air Travel & Other Indirect & Overseas travels which are done for business purposes \\
\cline { 2 - 4 } & Business Related Vehicle Travel & Other Indirect & Travels which are done for business purposes \\
\cline { 2 - 4 } & Car Allowance & Other Indirect & Private vehicle uses for business activities \\
\hline Office Activity & Paper Use & Other Indirect & Use of paper for the business activities \\
\hline
\end{tabular}

\section{Research Methodology}

The research was carried out to solve a contemporary issue, reduction of GHG emissions through proper reporting mechanisms. On the other hand, the research had to be carried out in a real-life context and required an in-depth analysis. Yin [18] has stated that if the research problem is a contemporary one which requires real life context data to be analysed in depth, case study is the best approach for such research. Accordingly, case study method has been used in this research.

Table 4: Sources of GHG emissions in Hotels.

\begin{tabular}{|c|c|c|}
\hline Case Study & & Designation of the Respondent \\
\hline Hotel $\mathbf{1}$ (H1) & R1 & Manager Quality Certifications \\
\hline \multirow{2}{*}{ Hotel 2 (H2) } & R2-a & Chief Engineer \\
\cline { 2 - 3 } & R2-b & Manager Sustainability \\
\hline \multirow{3}{*}{ Hotel 3 (H3) } & R3-a & Chief Engineer \\
\cline { 2 - 3 } & R3-b & Human Resource Manager \\
\cline { 2 - 3 } & R3-c & Manager Purchasing \\
\hline \multirow{2}{*}{ Hotel 4 (H4) } & R4 & Manager-Sustainability \\
\hline \multirow{2}{*}{ Hotel 5 (H5) } & R5-a & Chief Engineer \\
\cline { 2 - 3 } & R5-b & Manager Purchasing \\
\hline
\end{tabular}

As the case studies for the research, large hotels (Hotels which have more than 250 rooms) were selected. Focus was on the business capital of Sri Lanka and the hotels situated in that region. Accordingly, the hotels located in the Colombo city were selected for the study. All the hotels taken into the study belong to the five-star category and are located right in the center of the Colombo suburb. Following professionals (shown in Table 4) of the selected hotels were interviewed for the data collection purpose.

Semi structured interviews were conducted for the data collection purposes. Most common technique used for textual data analysis is content analysis. Content analysis technic is mostly used to analyze texts, interview data or newspapers [19]. Primary focus of the interviews was on identifying the availability of GHG emission reporting mechanism. Content analysis was used to identify this factor. The same approach was used to measure the knowledge level of the respondents regarding the GHG emission reporting and categories of emission recording. Content analysis enabled the researcher to identify the key sources of emissions within the hotel premises. The outline for the proposed GHG emission reporting guideline was prepared based on the information collected in the literature review as well as the information collected through interviews.

\section{Findings of the Empirical Study}

Section-I of the semi structured interview was focused on capturing the availability of a GHG Emission reporting mechanism in the selected case studies.

Accordingly, it was found that two of the selected case studies had partial mechanisms of reporting GHG emissions. These hotels were reporting the energy related emissions as a compulsory requirement of their hotel chains. Other three hotels had no mechanism for emission reporting. H2, H3 and H5 were three of the oldest hotels of Sri Lanka and one of these was also 
a part of a global hotel chain. Yet none of these case studies had a proper reporting mechanism.

Accordingly, majority of the case studies did not have a GHG reporting mechanism and none of them had a reporting mechanism that covered all the areas of GHG Emissions.

\section{Awareness of professionals involved in the hotels about emission reporting}

In order to implement a GHG emission reporting mechanism in a hotel, the professionals employed in that hotel should be aware about the process. Therefore section 1 of the semi structured interview was focused on this area. Awareness of the employees were checked with related to the three key areas in which the emissions are recorded. Figure 2 indicates the awareness levels of the respondents about each of the emission sectors. It was evident that majority of the respondents were having a less awareness about the GHG emission process. Out of the three sectors least awareness was on the Indirect Scope 2. Awareness on direct emission was comparatively higher.

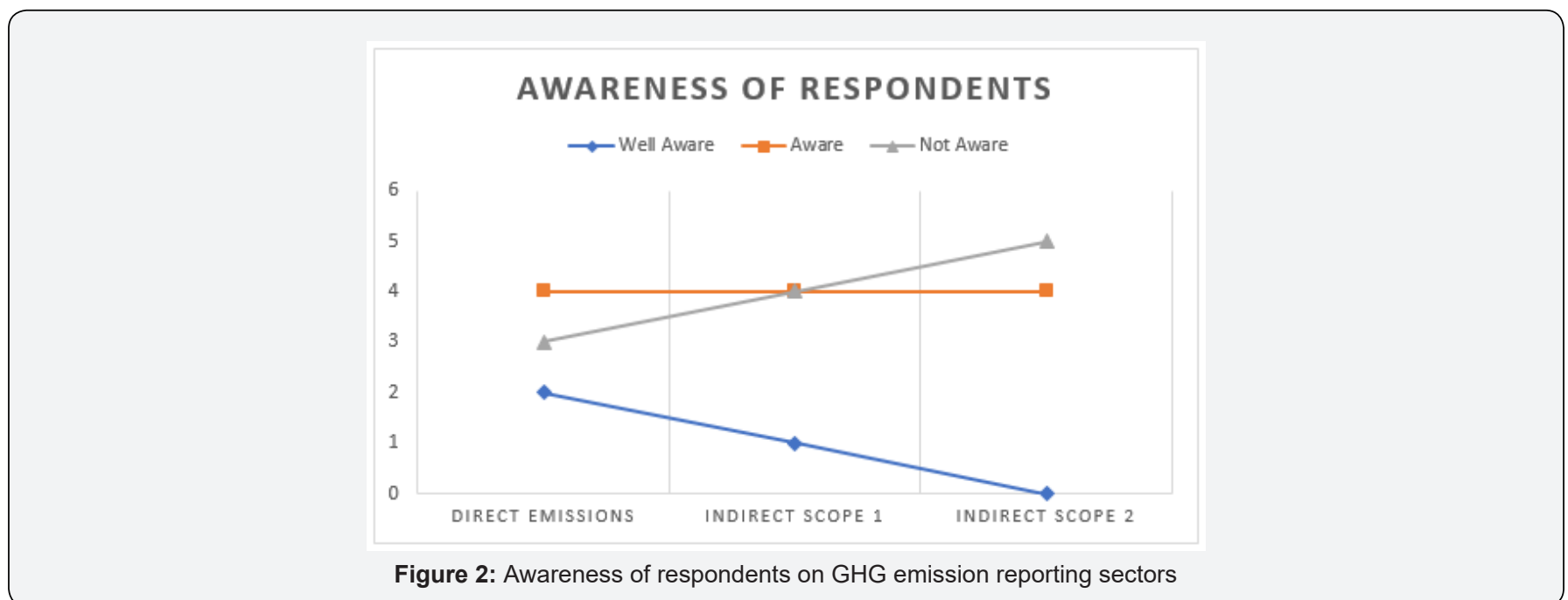

\section{Sources and levels of greenhouse gas emissions}

Section 2 of the interview was focused on gathering data related to sources of direct emissions. The initial focus was on the direct emissions sector. Operations of the hotels which directly emit gases to the atmosphere comes under this category. All the respondents indicated that direct emission sources should comprise with the following sectors.

a) Emissions from Generator Operations.

b) Emissions from Boiler Operations.

c) Emissions from LP Gas usage.

d) Emissions from other fuel combusting operations within the premises.

\section{Indirect energy emissions}

Second category of GHG emission reporting is indirect emissions. Under this category emissions recorded from the usage of purchased electricity will be taken into consideration. Majority of the respondents were aware about this aspect and two hotels were already recording emissions related to this sector.

\section{Indirect (scope 2) emissions}

This is the third sector of emissions that is included in the reporting process. Under this category all the emission impacts which does not come under the above two sectors are taken into consideration. Mainly the emissions occurring through travel related activities (vehicles not owned by the company), outsourced activities and waste disposal are recorded under this section.

Respondents indicated several areas to be added into this section that would have a considerable impact to the emissions. Following areas were indicated as key inclusions for these sections.
a) Guest Travel
b) Guest Meals
c) Paper use
d) Waste disposal
e) Employee travel

According to the empirical findings it is evident that none of the selected hotels had a complete GHG emission reporting mechanism. Even though two hotels were practicing the reporting mechanism, they were not fully aware about the entire process. Neither had they practiced the process internally. Empirical findings also indicated that the knowledge level of the professionals regarding the GHG emission reporting and its attributes are also low. Therefore, it is essential to take necessary measures to improve the knowledge of the employees about the process and its importance. 


\section{Proposed Outline}

Based on the literature findings and the empirical findings an outline has been developed. The process of GHG emission reporting is a combination of different processes. It is essential to follow these steps closely to implement a successful reporting mechanism.

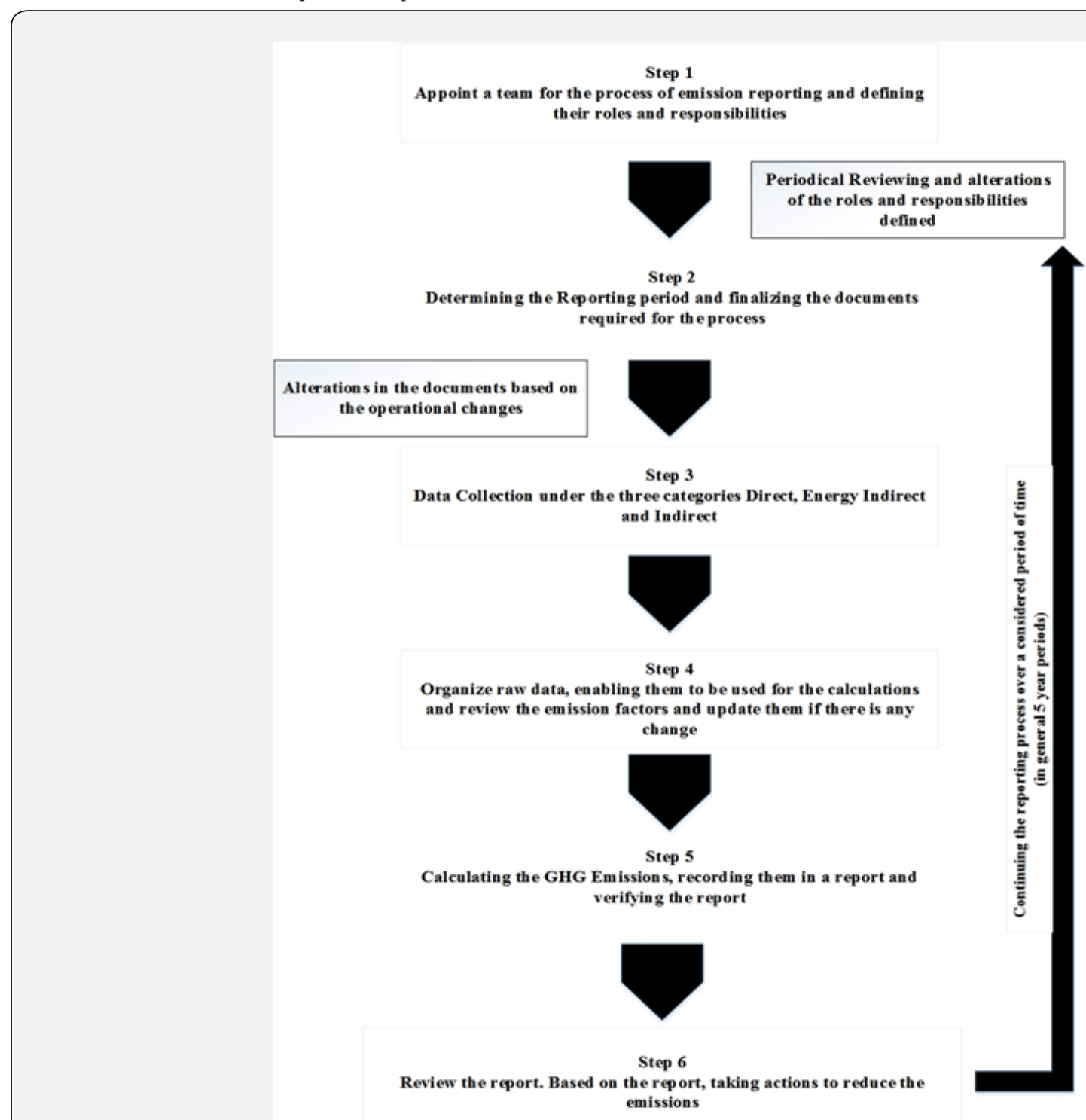

Figure 3: General Procedure to be followed.

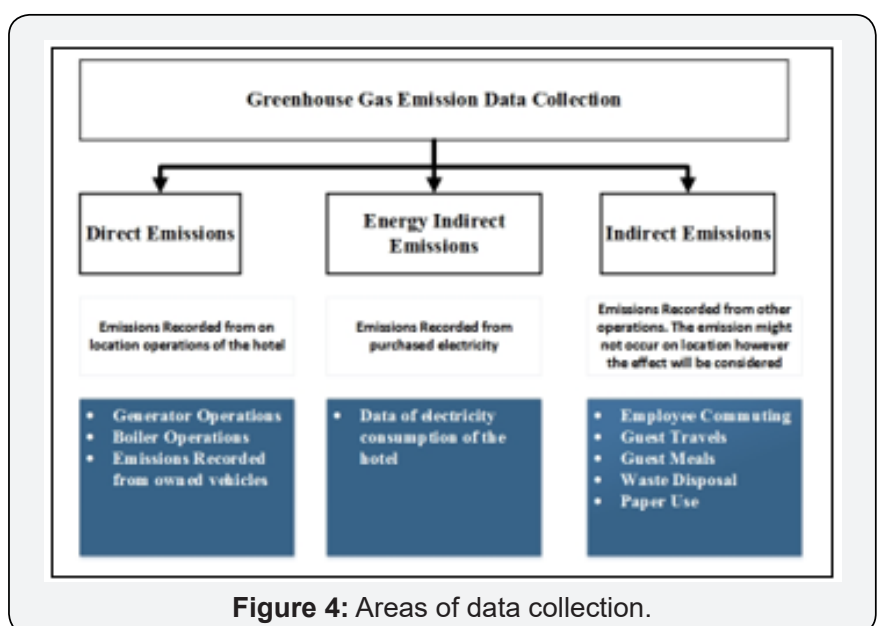

Figure 4: Areas of data collection.

In order to establish a GHG emission reporting mechanism it is essential to follow the general procedure indicated in Figure 3. GHG emissions of the hotel sector shall be recorded under the sectors shown in Figure 4. These have been derived from the empirical findings. It was identified through the literature review that data related to GHG emissions shall be collected under three main categories. It was further clarified through the research findings and activities in the hotel can be categorized under these three sectors. Research findings have enabled the researcher to determine the specific operations that comes under each sector [20].

\section{Conclusion and Recommendations}

Climate change has been recognized as one of the greatest challenges of the $21^{\text {st }}$ century. GHG emissions have a significant 
impact to the world climate change. Mitigating the emissions have become a key challenge to the world. The main objective of this research was to formulate the outline to develop a GHG emission reporting mechanism for the Sri Lankan hotel industry. Accordingly, the study was conducted among five of the five-star hotels in the commercial capital of Sri Lanka and it was found that none of the selected cases were having a complete GHG emission reporting mechanism. Based on the literature findings key elements required for GHG emission reporting in hotels were identified and the collected data were used to measure the emission levels of each hotel. Through this it was identified that energy indirect sector had the most significant impact to the total emissions of the hotels. It was also recognized that direct emission data were recorded by two of the selected cases. The study also confirmed the fact that no hotel had a proper in-house GHG emission calculation process. Calculations further indicated that the emissions of the hotels had a significant impact to the total GHG emissions of the country.

It was also identified that the knowledge on GHG emission reporting was comparatively low amongst the professionals of the hotels. In order to reduce the emissions, it is necessary to have a comprehensive knowledge about it. Therefore, researcher recommends carrying out training programs and knowledge sharing sessions on this topic to improve the knowledge of the professionals involved in hotel operations.

Formulated outline for GHG emission reporting process has identified several key elements. All these elements have a significant impact to the outcome of the process. Industry practitioners need to be aware about all these elements to prepare an effective emission report.

GHG emission reporting has been recognized as one of the key primary steps of initiating sustainability. With the rising global temperatures, carbon footprint reduction also has become a widely addressed aspect. Therefore, initiating a sustainability concept in a key sector like hotels will have a significant impact on the global carbon reduction effort. This study has provided the initial impetus by identifying the key areas of GHG emission reporting and thus developing a framework to initiate GHG emission reporting in the Hotel sector. This can be used as a primary tool to begin the emission reporting process within the hotel sector and thereby develop a standard emission reporting method that can be adopted to report emissions of hotels. This study will be an ideal guidance for the professionals engaged in the hotel industry to initiate the process of creating a greener future through reduced environmental damage.

\section{References}

1. United Nations World Tourism Organization [UNWTO] (2014) UNWTO Tourism Highlights (2014 Edition), Spain: UNWTO.
2. United Nations World Tourism Organization [UNWTO] (2016) UNWTO Tourism Highlights (2016 Edition), Spain: UNWTO.

3. Sri Lankan Tourism Development Authority [SLTDA] (2012) Annual Statistical Report (2012). Sri Lanka: SLTDA.

4. Deng SM (2003) Energy and water uses and their performance explanatory indicators in hotels in Hong Kong. Energy and Buildings 35(8): 775-784.

5. Ricaurte E (2011) Developing a sustainability measurement framework for hotels: Toward an industry-wide reporting structure.

6. Joshep HK, Yik LFWH, Man CS (2012) Carbon audit: a Literature review and an empirical study on a hotel. 30(9/10): 417-431.

7. Dascalaki E, Balaras CA (2004) XENIOS-a methodology for assessing refurbishment scenarios and the potential of application of RES and RUE in hotels. Energy and Buildings 36(11): 1091-1105.

8. Scheuer C, Keoleian GA, Reppe P (2003) Life cycle energy and environmental performance of a new university building: Modelling challenges and design implications. Energy and Buildings 35(10): 1049-1064.

9. WRI (World Resources Institute) (2014) Climate Analysis Indicators Tool (CAIT) 2.0: WRI's climate data explorer.

10. IPCC (2014) Summary for Policymakers. Climate Change 2014: Synthesis Report. Contribution of Working Groups I, II and III to the Fifth Assessment Report of the Intergovernmental Panel on Climate Change.

11. Intergovernmental Panel on Climate Change (2007) Climate Change 2007: Synthesis Report. Geneva: IPCC.

12. Ramachandra TV, Aithal BH, Sreejith K (2015) GHG footprint of major cities in India. Renewable and Sustainable Energy Reviews 44(2): 473495.

13. Indian Network for Climate Change Assessment (INCCA) (2010) Climate Change and India: a 4X4 Assessment a Sectoral and Regional Analysis for 2030S, p. 160.

14. Dubois G, Ceron JP (2006) Tourism/Leisure Greenhouse Gas Emissions Forecasts for 2050: Factors for Change in France. Journal of Sustainable Tourism 14(2): 172-191.

15. United Nations World Tourism Organization [UNWTO] (2011) Tourism and Climate Change. Spain: UNWTO.

16. Santamouris M, Balaras CA, Dascalaki E, Argiriou A, Gaglia, A (1996) Energy conservation and retrofitting potential in Hellenic hotels. Energy and Buildings 24(1): 65-75.

17. International Organization for Standardization, ISO 14064, Geneva, Switzerland, 2006.

18. Yin R (2011) Qualitative research from start to finish. ( $1^{\text {st }}$ edn), New York: Guilford Press.

19. Hancock B, Ockleford E, Windridge K (2009) An introduction to qualitative research. The NIHR RDS for the East Midlands: Yorkshire \& the Humber.

20. Khemiri A, Hassairi M (2005) Development of energy efficiency improvement in the Tunisian hotel sector: a case study. Renewable Energy 30(6): 903-911. 


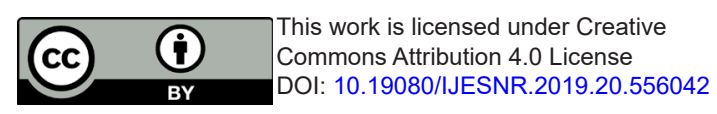

\section{Your next submission with Juniper Publishers will reach you the below assets}

- Quality Editorial service

- Swift Peer Review

- Reprints availability

- E-prints Service

- Manuscript Podcast for convenient understanding

- Global attainment for your research

- Manuscript accessibility in different formats ( Pdf, E-pub, Full Text, Audio)

- Unceasing customer service

Track the below URL for one-step submission https://juniperpublishers.com/online-submission.php 